\title{
APLICABILIDADE DA CONVENÇÃO DE NOVA IORQUE SOBRE RECONHECIMENTO E HOMOLOGA̧ÇÃO DE SENTENÇAS ARBITRAIS ESTRANGEIRAS PELOS TRIBUNAIS BRASILEIROS
}

\begin{abstract}
APPLICABILITY OF THE NEW YORK CONVENTION ON RECOGNITION AND ENFORCEMENT OF FOREIGN ARBITRAL AWARDS BY BRAZILIAN COURTS
\end{abstract}

${ }^{1}$ Flavia Foz Mange

\section{RESUMO}

Este artigo analisa a aplicabilidade da Convenção de Nova Iorque sobre reconhecimento e Homologação de Sentenças Arbitrais Estrangeiras pelos tribunais superiores do Brasil. Partese de hipótese que os Tribunais Superiores não aplicam o referido tratado internacional, mesmo após a sua internalização ao ordenamento jurídico brasileiro pelo Decreto 4.311 12002. Para verificar tal hipótese é realizado um estudo empírico analisando mais de 50 decisões em pedidos de homologação de sentenças arbitrais estrangeiras.

Palavras-chave: Arbitragem, Homologação, Tratado internacional, Tribunais superiores

\begin{abstract}
This article will analyze the applicability of the New York Convention about Recognition and Enforcement of Foreign Arbitral Awards by Brazilian superior courts. The hypothesis of the Author is that the superior tribunals do not apply the herein mentioned international treatise even after its incorporation to the Brazilian legal order by Decree 4.311/2002. To verify the hypothesis, an empirical research is undertaken analyzing more than 50 requests to enforce foreign arbitral awards.
\end{abstract}

Keywords: Arbitration, Enforcement, International treatise, Superior courts

\footnotetext{
${ }^{1}$ Pós-Doutora e professora da Universidade Estadual Paulista Júlio de Mesquita Filho - UNESP, São Paulo, SP.(Brasil). E-mail: flaviamange@ gmail.com.
} 


\section{INTRODUÇÃO}

O presente artigo visa analisar a aplicabilidade da Convenção das Nações Unidas sobre Reconhecimento e Homologação de Sentenças Arbitrais Estrangeiras ("Convenção de Nova Iorque") pelo ordenamento jurídico brasileiro. Parte-se da hipótese que a referida convenção, embora tenha cumprido com todo o iter procedimental necessário para sua internalização, inclusive com a promulgação pelo Decreto n. 4.311 de 23 de julho de 2002 ("Decreto 4.311/2002), não é aplicada pelos tribunais pátrios, prevalecendo o disposto nos artigos 38 e 39 da lei n. 9.307 de 23 de setembro 1996 ("Lei de Arbitragem") e não o texto do tratado internacional com eficácia no ordenamento interno.

Para verificar a hipótese acima, serão analisados as decisões do STF e STJ em matéria de homologação de sentença arbitral estrangeira, por meio de um estudo empírico de coleta de decisões e mapeamento da fundamentação destas decisões.

Antes de adentrar à análise jurisprudencial, faz-se necessário apresentar o contexto da edição da lei de arbitragem e equiparar o conteúdo dos seus artigos 38 e 39 com o do artigo $\mathrm{V}(1)$ e $\mathrm{V}(2)$ da Convenção de Nova Iorque $(i)$, além de discorrer sobre a incorporação do referido tratado internacional ao ordenamento brasileiro (ii). A terceira parte deste artigo discorrerá sobre a metodologia e critérios de busca para o estudo empírico e trará as principais conclusões e evidências da pesquisa jurisprudencial (iii); por fim, será analisada a reforma da Lei de Arbitragem ocorrida em 2015 (lei n. 13.125 de 26 de maio 2015 ou Lei 13.125/2015) com enfoque no que diz respeito aos artigos sobre homologação de sentença arbitral estrangeira e da perda da oportunidade de reforçar a prevalência do texto do tratado internacional (iv). Uma lista com informações detalhadas das decisões analisadas é apresentada no apêndice I. ${ }^{1}$

Não são objeto do presente estudo a relação do ordenamento jurídico brasileiro com os demais tratados internacionais sobre a temática, em especial, com a Convenção Interamericana sobre Arbitragem Comercial e Protocolo de Cooperação e Assistência Jurisdicional em Matéria Civil, Comercial, Trabalhista e Administrativa do Mercosul (Protocolo de Las Leñas). ${ }^{2}$

\footnotetext{
${ }^{1}$ Essa lista é apenas um resumo das análises realizadas no estudo empírico.
} 


\footnotetext{
${ }^{2}$ Respectivamente Decreto 1.902/1996 e Decreto 2.067/1996
}

\section{O CONTEXTO DA EDIC̃̃O DA LEI DE ARBITRAGEM E O CONTEÚDO DOS ARTIGOS 38 E 39 DA REFERIDA LEI EM COMPARAÇĀO AO ART. V DA CONVENÇÃO DE NOVA IORQUE}

A Lei de Arbitragem é considerada um grande marco para o avanço da arbitragem como meio de solução de conflitos no Brasil e foi muito comemorada. Entre as principais inovações da Lei de Arbitragem, merecem destaques o reconhecimento da eficácia e os efeitos da convenção de arbitragem (tanto na forma de compromisso arbitral como de cláusula compromissória) e a equiparação da sentença arbitral à judicial. ${ }^{3}$

Com relação à convenção de arbitral, com o reconhecimento dos efeitos negativos deste pacto e capacidade deste afastar as demandas do poder judiciário, o Brasil tornou vinculante a cláusula compromissória, anteriormente vista apenas como uma obrigação contratual e cujo descumprimento ensejava em perdas e danos. As alterações da Lei de Arbitragem foram acompanhadas de alterações no Código de Processo Civil, possibilitando a extinção do processo sem julgamento de mérito. ${ }^{4}$ A constitucionalidade de tal possibilidade da exclusão da apreciação pelo poder judiciário foi questionada perante o Supremo Tribunal Federal que, em 2002, declarou ser constitucional a Lei de Arbitragem e, em especial, os dispositivos que afastam a apreciação pelo poder judiciário de matérias sujeitas à arbitragem conforme convenção de arbitragem livremente pactuada entre as partes. ${ }^{5}$

Com relação à sentença arbitral, a Lei de Arbitragem equiparou a sentença arbitral à sentença judicial e estabeleceu que esta constitui título executivo. ${ }^{6}$ Ademais, tendo em vista que em 1996, quando da edição da lei de arbitragem, o Brasil não era parte da Convenção de Nova Iorque, a Lei de Arbitragem traz em seu bojo dispositivos sobre reconhecimento e homologação de sentenças arbitrais estrangeiras. À época, tal inserção foi comemorada uma vez que pôs fim a necessidade do duplo exequatur, qual seja, a exigência de que a sentença arbitral estrangeira fosse primeiramente reconhecida pelo judiciário no local de proferimento para após a decisão do judiciário que reconheceu a sentença arbitral ser objeto de uma ação de homologação de sentença arbitral estrangeira no Brasil. Ademais, a Lei de Arbitragem incorporou de maneira indireta os termos do artigo V da Convenção de Nova Iorque, estabelecendo no seus artigos 38 e 39 as possíveis alegações que podem ser realizadas para

\footnotetext{
${ }^{3}$ Para uma análise de histórico legislativo e contexto de promulgação da lei, ver CARMONA, 2009, pp. 1-26.

${ }^{4}$ Alteração no então art. 267,VII e 301, IX do Código de Processo Civil de 1973. Atualmente previsto no art. 337, X e 485,VII do Código de Processo Civil de 2015.

${ }^{5}$ BRASIL, Sentença Estrangeira $n^{o}$ 5.206-Reino da Espanha, STF, Relator Ministro Sepúlveda Pertence, julgamento finalizado em 12.12.2001.

${ }^{6}$ Art. 31. A sentença arbitral produz, entre as partes e seus sucessores, os mesmos efeitos da sentença proferida pelos órgãos do Poder Judiciário e, sendo condenatória, constitui título executivo
} 
obstar a homologação de uma sentença arbitral estrangeira. Também foi reconhecido o princípio pró-arbitragem (ou pró-homologação), invertendo o ônus da prova para a parte que quiser obstar o reconhecimento a execução no Brasil. Segue abaixo, a título ilustrativo, uma tabela comparativa entre a redação dos artigos 38 e 39 da Lei de Arbitragem e V(1) e V(2) da Convenção de Nova Iorque:

\begin{tabular}{|c|c|}
\hline Lei de Arbitragem & Convenção de Nova Iorque \\
\hline $\begin{array}{l}\text { Art. 38. Somente poderá ser negada a } \\
\text { homologação para o reconhecimento ou } \\
\text { execução de sentença arbitral estrangeira, } \\
\text { quando o réu demonstrar que: }\end{array}$ & $\begin{array}{l}\text { Artigo V } \\
\text { 1. O reconhecimento e a execução de uma sentença poderão } \\
\text { ser indeferidos, a pedido da parte contra a qual ela é } \\
\text { invocada, unicamente se esta parte fornecer, à autoridade } \\
\text { competente onde se tenciona o reconhecimento e a execução, } \\
\text { prova de que: }\end{array}$ \\
\hline $\begin{array}{l}\text { I - as partes na convenção de arbitragem eram } \\
\text { incapazes; }\end{array}$ & \multirow{2}{*}{$\begin{array}{l}\text { a) as partes do acordo a que se refere o Artigo II [cláusula de } \\
\text { arbitragem] estavam, em conformidade com a lei a elas } \\
\text { aplicável, de algum modo incapacitadas, ou que tal acordo não } \\
\text { é válido nos termos da lei à qual as partes o submeteram, ou, } \\
\text { na ausência de indicação sobre a matéria, nos termos da lei do } \\
\text { país onde a sentença foi proferida; ou }\end{array}$} \\
\hline $\begin{array}{l}\text { II - a convenção de arbitragem não era válida } \\
\text { segundo a lei à qual as partes a submeteram, } \\
\text { ou, na falta de indicação, em virtude da lei do } \\
\text { país onde a sentença arbitral foi proferida; }\end{array}$ & \\
\hline $\begin{array}{l}\text { III - não foi notificado da designação do } \\
\text { árbitro ou do procedimento de arbitragem, ou } \\
\text { tenha sido violado o princípio do } \\
\text { contraditório, impossibilitando a ampla } \\
\text { defesa; }\end{array}$ & $\begin{array}{l}\text { b) a parte contra a qual a sentença é invocada não recebeu } \\
\text { notificação apropriada acerca da designação do árbitro ou do } \\
\text { processo de arbitragem, ou lhe foi impossível, por outras } \\
\text { razões, apresentar seus argumentos; ou }\end{array}$ \\
\hline $\begin{array}{l}\text { IV - a sentença arbitral foi proferida fora dos } \\
\text { limites da convenção de arbitragem, e não foi } \\
\text { possível separar a parte excedente daquela } \\
\text { submetida à arbitragem; }\end{array}$ & $\begin{array}{l}\text { c) a sentença se refere a uma divergência que não está } \\
\text { prevista ou que não se enquadra nos termos da cláusula de } \\
\text { submissão à arbitragem, ou contém decisões acerca de } \\
\text { matérias que transcendem o alcance da cláusula de } \\
\text { submissão, contanto que, se as decisões sobre as matérias } \\
\text { suscetíveis de arbitragem puderem ser separadas daquelas } \\
\text { não suscetíveis, a parte da sentença que contém decisões } \\
\text { sobre matérias suscetíveis de arbitragem possa ser } \\
\text { reconhecida e executada; ou }\end{array}$ \\
\hline $\begin{array}{l}\text { V - a instituição da arbitragem não está de } \\
\text { acordo com o compromisso arbitral ou } \\
\text { cláusula compromissória; }\end{array}$ & $\begin{array}{l}\text { d) a composição da autoridade arbitral ou o procedimento } \\
\text { arbitral não se deu em conformidade com o acordado pelas } \\
\text { partes, ou, na ausência de tal acordo, não se deu em } \\
\text { conformidade com a lei do país em que a arbitragem ocorreu; }\end{array}$ \\
\hline VI - a sentença arbitral não se & e) a sentença ainda não se tornou obrigatória para as partes \\
\hline
\end{tabular}




\begin{tabular}{|l|l|}
\hline \multicolumn{1}{|c|}{ Lei de Arbitragem } & \multicolumn{1}{c|}{ Convenção de Nova Iorque } \\
\hline $\begin{array}{l}\text { tornado obrigatória para as partes, tenha sido } \\
\text { anulada, ou, ainda, tenha sido suspensa por } \\
\text { órgão judicial do país onde a sentença arbitral } \\
\text { for prolatada. }\end{array}$ & $\begin{array}{l}\text { ou foi anulada ou suspensa por autoridade competente do } \\
\text { proferida. }\end{array}$ \\
\hline $\begin{array}{l}\text { Art. 39. A homologação para o conforme a lei do qual, a sentença tenha sido } \\
\text { reconhecimento ou a execução da sentença } \\
\text { arbitral estrangeira também será denegada se o } \\
\text { Superior Tribunal de Justiça constatar que: }\end{array}$ & $\begin{array}{l}\text { Aambém poderão ser recusados caso a autoridade competente } \\
\text { do país em que se tenciona o reconhecimento e a execução } \\
\text { constatar que: }\end{array}$ \\
\hline $\begin{array}{l}\text { I - segundo a lei brasileira, o objeto do litígio } \\
\text { não é suscetível de ser resolvido por } \\
\text { arbitragem; }\end{array}$ & $\begin{array}{l}\text { a) segundo a lei daquele país, o objeto da divergência não é } \\
\text { passível de solução mediante arbitragem; ou }\end{array}$ \\
\hline $\begin{array}{l}\text { II - a decisão ofende a ordem pública } \\
\text { nacional. }\end{array}$ & $\begin{array}{l}\text { b) o reconhecimento ou a execução da sentença seria } \\
\text { contrário à ordem pública daquele país. }\end{array}$ \\
\hline
\end{tabular}

Embora haja pequenas diferenças nos textos, de maneira geral objeto e inclusive a forma de estruturação dos artigos 38 e 39 da Lei de Arbitragem são bastante semelhantes aos artigos $\mathrm{V}(1)$ e $\mathrm{V}(2)$ da Convenção de Nova Iorque. ${ }^{7}$ À época tal semelhança foi intencional e bastante comemorada por possibilitar ao Brasil, de certa forma, seguir os padrões internacionais e ser visto pela comunidade internacional como um país pró-arbitragem ou "amigo" da arbitragem. ${ }^{8}$

Já prevendo a possibilidade do Brasil vir a ratificar a Convenção de Nova Iorque ou outro tratado internacional sobre a arbitragem, a lei de arbitragem traz previsão expressa sobre conflito entre a Lei de Arbitragem e tratado internacional:

Art. 34. A sentença arbitral estrangeira será reconhecida ou executada no Brasil de conformidade com os tratados internacionais com eficácia no ordenamento interno e, na sua ausência, estritamente de acordo com os termos desta Lei. (destaques acrescentados)

De acordo com o entendimento pacificado pela jurisprudência pátria, ${ }^{9}$ tal previsão sequer seria necessária uma vez que tratados internacionais posteriores com eficácia no

\footnotetext{
${ }^{7}$ Para uma comparação mais detalhada veja: GAMA JÚNIOR (2005) e LEE (2007).

${ }^{8}$ Tradução livre do termo usual no âmbito internacional "arbitration friendly."

${ }^{9}$ Nesse sentido, vide BRASIL, STF, Carta Rogatória 8.279-Argentina. Para uma análise doutrinária, vide RESEK, 2011, p. 102-103; VARELLA, 2012, p. 88-94 e BINENBOJN, 2000.
} 
ordenamento interno devem, necessariamente e independente de previsão legal, prevalecer sobre normas de direito interno anteriores.

\section{A INCORPORAÇÃO DA CONVENÇÃO DE NOVA IORQUE AO ORDENAMENTO JURÍDICOBRASILEIRO}

Considerando que o Decreto 4.311/2002 promulgou a Convenção sobre o Reconhecimento e a Execução de Sentenças Arbitrais Estrangeiras, sendo o referido decreto publicado no Diário Oficial da União em 24 de julho de 2002 e tendo entrado em vigor na mesma data da sua publicação, as decisões sobre homologação de sentenças arbitrais estrangeiras proferidas pelo Supremo Tribunal Federal (STF) até 2004 e pelo Superior Tribunal de Justiça (STJ) a partir de 2005 deveriam fundamentar-se exclusivamente no texto da Convenção de Nova Iorque, tratado internacional com eficácia no ordenamento brasileiro. O próximo item irá analisar as decisões do STF e STJ sobre a questão, com objetivo de verificar a veracidade ou não da hipótese traçada na introdução de que, embora devidamente ratificado e promulgado por decreto presidencial publicado no diário oficial, o tratado internacional conhecido como Convenção de Nova Iorque não é aplicado pelos tribunais brasileiros, prevalecendo o texto de legislação doméstica anterior.

Note-se que além do artigo V, o artigo II da Convenção de Nova Iorque que trata da questão da eficácia da convenção de arbitragem ${ }^{10}$ que também é matéria disciplinada na lei de arbitragem brasileira e, possivelmente, também não é evocado pelos tribunais pátrios. Ocorre, contudo, que a análise a validade das convenções de arbitragem são realizadas de maneira descentralizada em diversos tribunais estaduais e não são objeto do estudo deste trabalho. $\mathrm{O}$ foco da pesquisa jurisprudencial será apenas os pedidos de homologação de sentença arbitral estrangeira e aplicação da Convenção de Nova Iorque pelos tribunais superiores, referências ao artigo II da convenção serão realizadas na medida em que forem mencionadas pelos tribunais superiores nas decisões de pedidos de homologação.

\footnotetext{
10 “Artigo II 1. Cada Estado signatário deverá reconhecer o acordo escrito pelo qual as partes se comprometem a submeter à arbitragem todas as divergências que tenham surgido ou que possam vir a surgir entre si no que diz respeito a um relacionamento jurídico definido, seja ele contratual ou não, com relação a uma matéria passível de solução mediante arbitragem.

2. Entender-se-á por "acordo escrito" uma cláusula arbitral inserida em contrato ou acordo de arbitragem, firmado pelas partes ou contido em troca de cartas ou telegramas.

3. O tribunal de um Estado signatário, quando de posse de ação sobre matéria com relação à qual as partes tenham estabelecido acordo nos termos do presente artigo, a pedido de uma delas, encaminhará as partes à arbitragem, a menos que constate que tal acordo é nulo e sem efeitos, inoperante ou inexeqüível."
} 


\section{AS DECISÕES DO STF E STJ EM MATÉRIA DE HOMOLOGAÇÃO DE SENTENÇA ARBITRAL ESTRANGEIRA}

A motivação para realização desta pesquisa empírica partiu da análise do relatório de pesquisa realizada em parceria entre a Fundação Getulio Vargas (FGV) e o Comitê Brasileiro de Arbitragem (CBAr) que analisou de maneira empírica as decisões envolvendo o tema da homologação da sentença arbitral estrangeira entre a promulgação da Lei de Arbitragem em 1996 e 2007 (MANGE et. al, s/d). Neste relatório, no qual foram analisadas 32 decisões, verificou-se um pequeno número de decisões fundamentadas na Convenção de Nova Iorque o que ensejou a seguinte nota pelos pesquisadores:

Embora o grupo de trabalho entenda que após a ratificação da Convenção de Nova Iorque a fundamentação das decisões de homologação de sentenças arbitrais estrangeiras devessem fundamentar-se na Convenção de Nova Iorque, optou-se por não utilizar a fundamentação na Convenção de Nova Iorque como critério de tecnicidade. Tal posicionamento foi adotado em decorrência da semelhança entre os dispositivos dos artigos (“arts.") 38 e 39 da Lei 9.307/96 e o art. V da Convenção de Nova Iorque. (MANGE et al, s/d, p. 15)

Passados quase 10 anos da referida pesquisa e quase 15 da promulgação da Convenção de Nova Iorque pelo Decreto 4.311/2002, verificou-se a necessidade de atualizar a referida pesquisa empírica e de analisar como o STJ tem fundamentado as decisões sobre homologação de sentenças arbitrais estrangeiras.

Nesse sentido, foram realizados dois trabalhos de pesquisa em paralelo.

Primeiro foi realizada uma pesquisa fonética no site do STJ buscando especificamente termos da Convenção de Nova Iorque, seja pelo número do decreto, seja pela nomenclatura, e comparando aos resultados das buscas pelos artigos específicos sobre homologação de sentença arbitral estrangeira da Lei de Arbitragem, conforme descrito no item 3.1 abaixo. ${ }^{11}$

Após, seguindo a metodologia da pesquisa realizada na parceria FGV/CBAr e buscando complementar a pesquisa anterior, foram realizadas buscas pelos termos "sentença estrangeira contestada" e "arbitral” ou "arbitragem" para o período entre 01.2008 e 12.2015. O resultado dessa pesquisa, incorporando as decisões pós promulgação do Decreto 4.311/2002 já analisadas pela pesquisa realizada na parceria FGV-CBAr em 2007 foram compiladas na planilha constante do Anexo I e serão analisadas a seguir no item 3.2.

\footnotetext{
${ }^{11}$ Considerando a transferência da competência sobre a questão do STF ao STJ no final de 2004 com a Emenda Constitucional n. 45/2004, é importante notar que o período entre agosto de 2002 e final de 2004 no STF não foi considerado para fins desta pesquisa fonética.
} 


\subsection{Pesquisa fonética}

A pesquisa utilizando o critério de busca "legislação" e incluindo o Decreto 4.311 no período de 01.08.2002 até 31.12.2015 não obteve nenhum resultado:

\section{Legislação: Decreto}

Número: 4.311

\section{Ocorrências: 0}

Utilizando a busca boleana e incluindo as palavras "convenção" e "nova" e "Iorque" no mesmo período são encontrados 9 acórdãos e 1 informe.

\section{Pesquisa Livre: "convenção" e "nova" e "Iorque" \\ Acórdãos: Ocorrências: 09 \\ Informativos de Jurisprudência: 01}

Dentre os 9 acórdãos, 5 são de Sentenças Estrangeiras Contestadas ${ }^{12}$ (“SEC”) objeto da presente análise. Desses 5 acórdãos, 1 trata de sentença estrangeira envolvendo a Convenção de Nova Iorque sobre Prestação de Alimentos no Estrangeiro e os outros 4 acórdãos sobre o tema ${ }^{13}$ serão analisadas no conjunto de todas as sentenças arbitrais estrangeiras estudadas abaixo no item 3.2. Os demais casos são Recursos Especiais ou Habeas Corpus que também fazem referência à Convenção de Nova Iorque sobre Prestação de Alimentos no Estrangeiro ou são casos envolvendo procedimentos arbitrais no Brasil e não homologações de sentenças estrangeiras, objeto do presente estudo.

O informe é sobre um Recurso Especial (REsp n. 1.213.544-RJ) que discute sobre a necessidade de homologação de uma de sentença arbitral proferida no Brasil de acordo como regulamento de arbitragem da Câmara de Comércio Internacional (CCI). Neste caso, a discussão se deu em torno do critério de nacionalidade da sentença arbitral e foi realizada referência ao art. I da Convenção de Nova Iorque que deixou para as legislações nacionais determinarem o critério de nacionalidade da sentença arbitral. ${ }^{14}$

\footnotetext{
${ }^{12}$ Sentença Estrangeira Contestada (SEC) é uma classe processual estipulada pelo STJ que trata justamente 13 Sobre os pedidos de homologação de sentenças estrangeiras, tanto arbitrais como judiciais.

${ }^{13}$ São elas as SEC n' ${ }^{\circ}$. 5.782; 8847; 3709 e 856.

${ }^{14}$ EXECUÇÃO. SENTENÇA ARBITRAL. HOMOLOGAÇÃO. STJ. A sentença arbitral que se quer executar deriva de procedimento arbitral instaurado mediante requerimento à Corte Internacional de Arbitragem da Câmara de Comércio Internacional, com sede em Paris, França. Contudo, ela foi proferida em língua portuguesa, no Brasil (por escolha consensual das partes), por árbitro brasileiro e com aplicação do Direito brasileiro em seu mérito. Discute-se, ao cabo, a necessidade de prévia homologação pelo STJ desse título, tido pela recorrente como sentença arbitral estrangeira, para que se torne apto a aparelhar a execução. Quanto a isso, vê-se que a execução, para ser regular, tem que se amparar em título executivo idôneo, entre os quais figuram a sentença arbitral (art. 475-N, IV, do CPC) e a sentença estrangeira homologada (inciso VI desse mesmo dispositivo). Já o art. 31 da Lei n. 9.307/1996 (Lei de Arbitragem) conferiu ao laudo arbitral nacional os efeitos de sentença judicial e, por sua vez, a jurisprudência do STF trouxe o entendimento de que os laudos arbitrais estrangeiros necessitam de homologação, o que foi incorporado à Lei de Arbitragem (vide
} 
Por outro lado, a pesquisa legislativa já nos traz entre os critérios de busca a Lei de Arbitragem, permitindo inclusive a pesquisa detalhada por artigos. Foram realizadas as pesquisas pelos artigos 38 e 39 no período de 01.08.2002 até 31.12.2015, sendo encontradas 36 ocorrências do primeiro e 33 do segundo:

Legislação: Lei de Arbitragem

Artigo 38

Ocorrências: 36

Legislação: Lei de Arbitragem

Artigo 39

Ocorrências: 33

Já o artigo 34 da Lei de Arbitragem que faz referencia expressa à primazia dos tradados internacionais sobre o tema só obteve 7 referências no mesmo período:

Legislação: Lei de Arbitragem

Artigo 34

Ocorrências: $07^{15}$

Por esta pesquisa apenas, já é possível constatar que a Lei de Arbitragem ainda prevalece ao tratado internacional em vigor, não se verificando muitas referências à convenção. No entanto, por entender que a simples busca por critérios de pesquisa no site do STJ não traz a visão completa do status do tratado internacional em análise, optou-se por realizar uma pesquisa completa das sentenças arbitrais estrangeiras como se passa a demonstrar.

\subsection{Pesquisa em Sentenças Estrangeiras Contestadas (SEC) sobre Arbitragem}

Tendo em vista os baixos resultados encontrados com a pesquisa fonética buscando especificamente os termos da Convenção de Nova Iorque (seja pelo nome ou pelo número do Decreto), optou-se por atualizar a pesquisa realizada anteriormente e mapear todas as

seu art. 35). $\mathrm{O}$ art. $1^{\circ}$ da Convenção de Nova Iorque (promulgada pelo Dec. n. 4.311/2002) deixou para as legislações dos países a tarefa de eleger o critério que define a nacionalidade da sentença arbitral, daí os diferentes conceitos de sentença arbitral estrangeira constantes dos diversos ordenamentos jurídicos do cenário internacional. A legislação brasileira elegeu exclusivamente o critério geográfico (jus solis) - o local onde a decisão foi proferida - para a determinação da nacionalidade da sentença arbitral, tal como se constata da leitura do art. 34, parágrafo único, da Lei de Arbitragem. Assim, na hipótese, o simples fato de o procedimento arbitral ser requerido na corte internacional e se ter regido por seu regulamento não tem o condão de desnaturar a nacionalidade brasileira da sentença em questão, título idôneo a lastrear a execução, por si só dotado de eficácia, o qual não necessita de homologação judicial para ser executado. Precedentes citados: SEC 894-UY, DJe 9/10/2008; SEC 611-US, DJ 11/12/2006, e SE 1.305-FR, DJ 7/2/2008. REsp 1.214.554-RJ, Rel. Min. Nancy Andrighi, julgado em 24/5/2011.

${ }^{15}$ Destas 7, uma tratava-se de um Recurso Especial fora do escopo desta pesquisa e as outras 6 são as SEC n ${ }^{\circ}$ s. $11.969 ; 5.782 ; 11.529 ; 6.365 ; 4.439$ e 3.661 que serão analisadas junto com as demais SEC que tratam de sentenças arbitrais estrangeiras. 
sentenças estrangeiras que envolvessem matéria arbitral para a partir desse banco de dados analisar no universo das sentenças arbitrais estrangeiras submetidas à homologação no Brasil a fundamentação dos acórdãos.

Inicialmente foram incluídas no banco de dados da presente pesquisa as decisões nas SEC após a entrada em vigor do Decreto 4.311/2002 já mapeadas pela pesquisa realizada anteriormente (MANGE et al, s/d). Das 32 SEC analisadas naquela pesquisa, 23 foram trazidas para presente pesquisa. Após, o banco de dados foi atualizado incluindo decisões em pedidos de homologação de sentença arbitral estrangeira proferidos após a conclusão da pesquisa anterior. Neste novo período, foram localizadas mais 33 SEC envolvendo sentenças arbitrais estrangeiras. Desta forma, o banco de dados analisado contou com $56^{16}$ pedidos de homologação de sentenças estrangerias do STJ. ${ }^{17}$

Destas 56 SEC, apenas $11^{18}$ fazem menção à Convenção de Nova Iorque, ou seja, menos de $20 \%$ das decisões. Além do mais, diversas decisões fazem menção apenas no relatório, ao artigo II, em sede de embargos de declaração, ou mencionam o artigo da Convenção de Nova Iorque juntamente com o artigo da Lei de Arbitragem. Há apenas $4{ }^{19}$ que enfrentam expressamente a questão da aplicação do tratado internacional e da sua primazia sobre legislação nacional anterior, sendo três desses quatro em sede de Embargos de Declaração e em dois desses três embargos a questão não foi sequer apreciada. Apenas um único caso já na decisão da SEC discutiu-se a matéria a aplicou-se a Convenção de Nova Iorque.

Considerando a existência de poucos casos fazendo referência à Convenção de Nova Iorque, passa-se a analisa-los.

O primeiro caso que faz menção à Convenção de Nova Iorque é a SEC 856, julgada em 18.05.2005. Neste caso, houve menção ao artigo II da convenção como fundamento de validade da cláusula compromissória e não o artigo $\mathrm{V}$ como rol de causas para não homologação.

\footnotetext{
${ }^{16}$ Em diversas SEC há mais de uma decisão. Foram analisados o conjunto de decisões em cada SEC, incluindo em muitas delas decisões em Embargos de Declaração que podem vir a tratar do tema da aplicabilidade da Convenção de Nova Iorque ao sanar omissão ou obscuridade.

17 No período entre agosto de 2002 e dezembro de 2004 não houve julgamento de pedidos de homologação de sentença arbitral estrangeira no STF.

18 Em ordem cronológica, as SEC 856; SEC 967; SEC 866; SEC 507; SEC 611; SEC 831; SEC 978; SEC3660; SEC 3709; SEC 8847; SEC 5782.

19 Embargos de Declaração na SEC 866 que aplica critério da data de execução do contrato para não aplicar a Convenção ao caso e Embargos de Declaração na SEC 507 e na SEC 611 a questão foi levantada mas não enfrentada pelo STJ. Apenas na SEC 5782 a questão foi abordada na decisão e constatada a necessidade de aplicação do tratado internacional em vigor.
} 
A não menção ao artigo II da Convenção de Nova Iorque ensejou a oposição de Embargos de Declaração na SEC 967 que foram rejeitados.

A alegação de que Convenção de Nova Iorque teria derrogado os dispositivos da Lei de Arbitragem ${ }^{20}$ ensejou os Embargos de Declaração na SEC 866. Contudo, neste caso o STJ utilizou critério da data da celebração do contrato para fundamentar a não aplicação do tratado internacional:

Portanto, os vícios apontados não merecem acolhida, uma vez que a Convenção das Nações Unidas sobre o Reconhecimento das Sentenças Arbitrais Estrangeiras de 1958, (Convenção de Nova York), incorporada ao ordenamento brasileiro pelo Decreto $n^{\circ}$ 4.311, de 23 de julho de 2002, não vigia no Brasil à época da celebração dos contratos tidos como inadimplidos, sendo posterior, inclusive, ao requerimento da homologação (25 de fevereiro de 2002, cf. fl. 02). (Emb.Decl. na SEC 866, p. 8)

Tal decisão é totalmente contrária à jurisprudência sobre internalização de tratados internacionais no direito Brasileiro, bem como àquela que reconhece a aplicação da Lei de Arbitragem para contratos celebrados antes da sua entrada em vigor (CARMONA, 2009, p. 80).

Também foram opostos Embargos de Declaração nas SEC 507 e SEC 611 questionando a omissão à Convenção de Nova Iorque. Nessas oportunidades, nos dois casos, o STJ manteve a decisão embargada, sem discutir sobre a hierarquia ou eficácia da Convenção de Nova Iorque.

No final de 2007, na SEC 831, o STJ mencionou expressamente que não há contrariedade entre o disposto no artigo 35 e seguintes da Lei de Arbitragem e as disposições da Convenção de Nova Iorque e fundamentou sua decisão em ambos dispositivos, que se complementam segundo o Min. Arnoldo Esteves Lima:

Entretanto, porquanto válidas no país onde proferidas, as questões relativas ao reconhecimento e execução das sentenças arbitrais, proferida fora do território nacional têm por regência a Lei 9.307, de 23 de setembro de 1996 e, - a rigor - o que preconiza o art. 35 e seguintes da norma especial em comento e as disposições da Convenção de Nova York, com eficácia interna autorizada pelo Decreto $n^{\circ}$ 4311, de 23 de julho de 2002, as quais sem qualquer contrariedade, complementam-se em busca de solução de litígios no comércio internacional. (SEC 831, p. 7, destaques acrescentados).

\footnotetext{
20 “omissão e contradição, uma vez que os dispositivos da Lei no 9.307/96 já não vigem na ordem jurídica brasileira, derrogados que foram por lei especial superveniente, qual seja, a Convenção de Nova York, laborando o acórdão embargado, neste ponto, em contradição e omissão(...)” (Emb. Decl. na SEC 866, p. 3).
} 

Diversas decisões mencionam a Convenção de Nova Iorque, mas não dão qualquer relevância à sua aplicabilidade. Na SEC 978 a menção à Convenção de Nova Iorque ocorre de maneira indireta ao transcrever julgado anterior, SEC 856, que traz o tema a aplicação do artigo II da Convenção de Nova Iorque, conforme mencionado acima. A decisão da SEC 3.660 é fundamentada nos artigos 38(III) e 39, parágrafo único da Lei de Arbitragem, e a menção à Convenção de Nova Iorque é apenas em transcrição indireta da obra de ABBUD (2008). Na SEC 8.847 a menção Convenção de Nova Iorque, é en passant ao tratar sobre o procedimento arbitral e não ao discorrer sobre a homologação. ${ }^{21}$

Em 2012, na SEC 3.709 o STJ teve a oportunidade de comparar os dispositivos dos artigos 38(II) da Lei de Arbitragem e V(1)“a” da Convenção de Nova Iorque e fundamentou sua decisão nos dois diplomas legais conforme ementa e parte da decisão transcrita abaixo:

EMENTA: 1. A lei aplicável para disciplinar a representação das partes no procedimento arbitral, bem como a forma como podem manifestar seu ingresso no referido procedimento, é a lei a que as partes se submeteram ou, na falta dela, à do país onde a sentença arbitral foi proferida, cumprindo à parte demandada o ônus de demonstrar a violação a esses preceitos normativos. É o que dispõem a Lei 9.307/96 (art. 38, II) e a Convenção de Nova Iorque (art. V, 1, a).

(...)

3. Cumpre atentar, ademais, para o que dispõe art. 38, II, da Lei de Arbitragem, que traduz, no particular, o que constou do art. $\mathrm{V}, 1$, a da Convenção de Nova Iorque, de 1958, celebrada no âmbito das Nações Unidas e promulgada no Brasil pelo Decreto 4.311, de 23.07.02. Diz a Lei: (SEC 3.709, p. 1 e 12-13, destaques acrescentados)

No final de 2015, o famoso caso envolvendo a EDF e Engessa, a SEC 5.782, que discutia a possibilidade de homologação de sentença arbitral anulada na argentina, é o primeiro caso a tratar explicitamente da aplicação dos tratados internacionais com eficácia no ordenamento jurídico interno, esclarecendo já na sua ementa

HOMOLOGAÇÃO DE SENTENÇA ARBITRAL ESTRANGEIRA CONTESTADA. ARTIGO 34 DA LEI N. 9.307/1996. INCIDÊNCIA INICIAL DOS TRATADOS INTERNACIONAIS, COM EFICÁCIA NO ORDENAMENTO JURÍDICO INTERNO. APLICAÇÃO DA LEI DE ARBITRAGEM NA AUSÊNCIA DESTES. LAUDO ARBITRAL ANULADO NO PAÍS DE ORIGEM, COM SENTENÇA JUDICIAL TRANSITADA EM JULGADO. JUÍZO DE DELIBAÇÃO. DESCABIMENTO DO EXAME DO MÉRITO DA SENTENÇA ARBITRAL. IMPOSSIBILIDADE DA ANÁLISE DA DECISÃO

21 "13. O que importa considerar é que o rito adotado pelo tribunal arbitral seguiu as normas processuais da CCI e mostra conforme com a Convenção da Nações Unidas sobre o reconhecimento e a Execução de Sentença Arbitrais Estrangeiras de 1958 (Convenção de Nova Iorque).” (SEC 8.847 p. 8) 


\section{JUDICIAL ESTRANGEIRA. INDEFERIMENTO DA PRETENSÃO HOMOLOGATÓRIA.}

1. $O$ artigo 34 da Lei n. 9.307/1996 determina que a sentença arbitral estrangeira será homologada no Brasil, inicialmente, de acordo com os tratados internacionais com eficácia no ordenamento interno e que, somente na ausência destes, incidirão os dispositivos da Lei de Arbitragem Brasileira.

2. No caso em exame, a sentença arbitral que se pretende homologar foi anulada judicialmente pelo Poder Judiciário Argentino, com decisão transitada em julgado. 3. A legislação aplicável à matéria Convenção de Nova York, Artigo V(1)(e) do Decreto n. 4.311/2002; Convenção do Panamá, Artigo 5(1)(e) do Decreto n. 1.902/1996); Lei de Arbitragem Brasileira, Artigo 38, inciso VI, da Lei n. 9.307/1996; e Protocolo de Las Leñas, Artigo 20(e) do Decreto n. 2.067/1996, todos internalizados no ordenamento jurídico brasileiro não deixa dúvidas quanto à imprescindibilidade da sentença estrangeira, arbitral ou não, ter transitado em julgado para ser homologada nesta Corte Superior, comungando a doutrina pátria do mesmo entendimento.

(...) (SEC 5782, destaques acrescentados)

Em que pese a bela decisão do final do ano passado, não se pode dizer que houve uma mudança de posicionamento no STJ. Após a decisão supra cita, outros 3 casos foram decididos sem qualquer menção à convenção. Ademais, a SEC 11.969 ressalta a legislação aplicável à material da homologação de sentenças arbitrais estrangeiras:

1. É devida a homologação da sentença arbitral estrangeira quando atendidos os requisitos previstos nos arts. 34 a 40 da Lei 9.307/96, no art. 15 Lei de Introdução às Normas do Direito Brasileiro e nos arts. 216-A a 216-N do RISTJ, bem como constatada a ausência de ofensa à soberania nacional, à ordem pública e à dignidade da pessoa humana (Lei 9.307/96, art. 39; LINDB, art. 17; RISTJ, art. 216-F) (SEC 11.969)

Dessa forma, embora existam algumas decisões isoladas que fazem menção em partes distintas e por razões distintas à Convenção de Nova Iorque, são ainda raras as decisões fundamentadas na convenção, reconhecendo a incidência dos tratados internacionais.

\section{A REFORMA DA LEI DE ARBITRAGEM OCORRIDA EM 2015 (LEI N. 13.125 DE 2015).}

Em 2015, já mais de 10 anos após a promulgação da Convenção de Nova Iorque pelo Decreto 4.311/2002, foi concluída a reforma da Lei de Arbitragem com a introdução de diversas alterações pela Lei 13.129/2015. Importante notar que ao longo dos quase 20 anos de vigência da Lei de Arbitragem vários projetos legislativos de alteração do referido diploma legal tramitaram no congresso e sempre foram muito combatidos pela comunidade arbitral que entendia que a lei 9.307/1996 continha um texto adequado e ainda estava em processo de 
incorporação e interpretação pelo poder judiciário, precisando de um maior decurso de tempo para novas alterações. No entanto, em conjunto com reforma do Código de Processo Civil, uma reforma na Lei de Arbitragem parecia inevitável.

Nesse sentido, formou-se em 2012 uma comissão de juristas por requerimento do presidente do Senado Federal para elaboração da reforma da Lei de Arbitragem. Tal comissão foi inicialmente formada por juristas de ilibada reputação, mas com atuação majoritariamente processual. $^{22}$ Após quase 3 anos de tramitação foram discutidos diversos temas entre eles merece destaque para o presente artigo o tema "v. Direito Estrangeiro e Arbitragem Internacional" e "xii. Homologação de Sentença Estrangeira" (MAIA NETO; MUNIZ, 2015).

Os principais aspectos da reforma foram inclusão de vários novos artigos que tratam da possibilidade e regulamentam arbitragens envolvendo a administração pública e esclarecimentos de algumas questões procedimentais, incorporando entendimentos que já existiam na prática arbitral e eram reconhecidos pela jurisprudência. Em razão da Emenda Constitucional n. 45/2014 houve ajustes às referências ao Supremo Tribunal Federal, adequando estas ao Superior Tribunal de Justiça. Houve ainda exclusão de alguns artigos como, por exemplo, o caput do Artigo 25 e alteração da redação de diversos outros.

No que tange aos dispositivos sobre reconhecimento e homologação de sentenças arbitrais estrangeiras não houve mudanças significativas. O artigo 34 que dispõe sobre a primazia dos tratados internacionais com eficácia no ordenamento interno não foi alterado. Os demais artigos do 35 ao 40 tiveram alterações apenas para adequação às referências ao Superior Tribunal de Justiça ao invés de Supremo Tribunal Federal em razão da Emenda Constitucional supra citada e aos novos artigos do Código de Processo Civil. Em particular com relação aos fundamentos para possível indeferimento de um pedido de homologação constantes nos incisos dos artigos 38 e 39 não houve alteração.

Ao analisar a nota técnica apresentada ao Congresso Nacional por ocasião do projeto de alteração da lei, verifica-se que existe um item que trata especificamente dos “compromissos internacionais" (CONGRESSO NACIONAL, 2014). Tal item faz menção à

\footnotetext{
${ }^{22}$ Formaram a primeira comissão, além do Senador Marco Maciel, José Antonio Fichtner; Caio Cesar Rocha, José Rogério Cruz e Tucci Marcelo Rossi Nobre; Francisco Antunes Mussnich; Tatiana Lacerda Prazeres; Adriana Braghetta; Carlos Alberto Carmona; Eleonora Coelho; Pedro Paulo Guerra Medeiros, Silvia Rodrigues Pachikoski e Francisco Maia Neto. Posteriormente foram incluídos: Ellen Gracie Northfleet; André Chateaubriand Martins; José Roberto Castro Neves; Marcelo Henrique de Oliveira; Walton Alencar Rodrigues; Roberta Maria Rangel; Eduardo Pelegrini de Arruda Alvim e Adacir Reis.
} 
Convenção de Nova Iorque e detalha a sua entrada em vigor no Brasil, ${ }^{23}$ mas em momento algum discute a necessidade de manutenção dos artigos 38 e 39 na Lei de Arbitragem após a entrada em vigor do tratado internacional no ordenamento brasileiro.

Em conversas informais com membros da Comissão de Juristas que atuou na reforma da lei, verificou-se que o tema da necessidade dos artigos 38 e 39 da Lei de Arbitragem após a promulgação da Convenção de Nova Iorque sequer foi discutida pela comissão.

Dessa forma, perdeu-se uma oportunidade de revogar expressamente os artigos 38 e 39 da Lei de Arbitragem em razão de tratado internacional eficaz no Brasil. Embora tal medida sequer fosse necessária para se demandar a aplicação imediata da Convenção de Nova Iorque, a revogação expressa dos referidos artigos levaria a aplicação forçada dos dispositivos do tratado internacional.

\section{CONCLUSÕES}

A conclusão da pesquisa empírica é de que a hipótese traçada na introdução do presente artigo é verídica. Mesmo após a internalização da Convenção de Nova Iorque sobre reconhecimento e homologação de sentenças arbitrais estrangeiras pelo Decreto 4.311/2002 o STJ continua a fundamentar suas decisões em pedidos de homologação de sentenças arbitrais majoritariamente na Lei de Arbitragem. Ademais, mesmo havendo reforma na referida Lei de Arbitragem em 2015, não houve sequer discussão sobre eventual revogação dos dispositivos dos artigos 38 e 39 da referida lei em razão de tratado internacional posterior disciplinando a matéria.

No entanto, não se pode negar que existem alguns exemplos isolados de decisões com referência ou fundamentação na Convenção de Nova Iorque e, especialmente, a clareza do julgamento da SEC n. 5.782 no final de 2015. Neste caso, houve referência expressa ao artigo 34 da Lei de Arbitragem e da aplicação da Convenção de Nova Iorque, seguido do indeferimento com base nos artigos da Convenção de Nova Iorque. Embora tal acórdão seja recente, não se pode dizer que houve uma mudança no posicionamento do STJ, pois logo após houve outro julgamento, a SEC n. 11.969 sem qualquer menção à Convenção de Nova

\footnotetext{
23 “A Convenção sobre o Reconhecimento e a Execução de Sentenças Arbitrais Estrangeiras teve o seu texto aprovado pelo Congresso Nacional, por meio do Decreto Legislativo $\mathrm{n}^{\circ}$ 52, de 25 de abril de 2002. Em 7 de junho de 2002, o Brasil acedeu ao tratado que passou a vincular o país internacionalmente, depois de transcorridos noventa (90) dias do depósito do instrumento de acessão, em 4 de setembro de 2002. A Convenção de Nova York foi promulgada pelo Decreto $n^{\circ} 4.311$, de 23 de julho de 2002, quando passou a ter validade no plano interno. No plano internacional, a Convenção está em vigor desde 7 de junho de 1959." (CONGRESSO NACIONAL, 2014, p. 29).
} 
Iorque. Ademais, não apreciação da questão pelo STJ, mesmo quando ventilada por uma das partes em sede de embargos de declaração ${ }^{24}$ e a não aplicação da convenção com base no contrato ter sido celebrado antes da entrada em vigor do decreto que promulgou o tratado internacional $^{25}$ não condizem com a necessidade de segurança jurídica necessária nas relações comerciais internacionais e que a promulgação da Convenção de Nova Iorque buscava. Ademais, estaríamos diante de uma volta ao dualismo exacerbado, dando eficácia ao tratado internacional apenas por meio de uma legislação doméstica?

Ressalta-se que a importância dos tribunais superiores aplicarem a Convenção de Nova Iorque permitirá não apenas que o tratado internacional seja efetivamente aplicado no Brasil, mas também que o Brasil contribua com o desenvolvimento da jurisprudência sobre a aplicação da Convenção de Nova Iorque. ${ }^{26}$ Para promoção do conhecimento sobre a Convenção de Nova Iorque, Albert van den Berg, um dos maiores estudiosos sobre a referida convenção e sua aplicação pelos tribunais das mais diversas jurisdições, esteve no Brasil e proferiu palestra em 20 março de 2013 aos ministros do STJ (STJ, 2013) e divulgou o Guia do ICCA sobre a interpretação da convenção de Nova Iorque de 1958: um texto de referência para juízes (ICCA, 2012). A ocasião contou com a participação da Min. Ellen Gracie que encerrou o evento com a seguinte citação:

"A boa aplicação da Convenção de Nova Iorque é, sem dúvida, a pedra de toque para o desenvolvimento de um bom sistema arbitral."(STJ, 2013)

\footnotetext{
${ }^{24}$ Vide SEC 507 e SEC 611 analisadas no item 3.2 acima.

${ }^{25}$ Vide SEC 866 analisada no item 3.2 acima.

${ }^{26}$ Nesse sentido, vide Guia sobre a Interpretação da Convenção de Nova Iorque contendo jurisprudência dos mais variados países que aderiram à convenção (ICCA, 202)
}

\section{REFERÊNCIAS BIBLIOGRÁFICAS:}

ABBUD, André C. Homologação de Sentenças Arbitrais Estrangeiras. Atlas: São Paulo, 2008 .

BINENBOJN, Gustavo. Monismo e Dualismo no Brasil: Uma dicotomia Irrelevante. Revista da EMERJ. Rio de Janeiro: Tribunal de Justiça do Estado do Rio de Janeiro, v. 3, n. 9, 2000.

CARMONA, Carlos Alberto. Arbitragem e processo: um comentário à Lei n. 9.307/96. 3. ed. rev. atual. e ampl. São Paulo: Atlas, 2009. 
http://www2.camara.leg.br/documentos-e-pesquisa/publicacoes/estnottec/areas-daconle/tema5/2014_9932.pdf. Acesso em 30.março.2016.

GAMA JÚNIOR, Lauro da. O STJ e a Homologação de Sentenças Arbitrais Estrangeiras: Novas Perspectivas?. In Revista Brasileira de Arbitragem. v. 2 n. 5 jan/fev/mar 2005. Porto Alegre: Síntese; Curitiba: Comitê Brasileiro de Arbitragem, 2005, p. 62-66.

ICCA. Guia do ICCA sobre a interpretação da convenção de Nova Iorque de 1958: um texto de referência para juízes. Tradução Flavia Foz Mange (coord.). International Council for Commerical Arbitration, 2012. Disponível em: http://www.arbitrationicca.org/media/1/13320134139400/portuguese_guide_composite_for_website_final.pdf. Acesso em 09.abril.2016.

LEE, João Bosco. A homologação de Sentença Arbitral Estrangeira. In Estudos em Homenagem ao Prof. Guido Fernando da Silva Soares, In Memoriam, Selma Ferreira Lemes, Carlos Alberto Carmona e Pedro Batista Martins (cords). São Paulo: Atlas, 2007.

MAIA NETO, Francisco; MUNIZ, Joaquim de Paiva (Coords). Reforma da Lei de Arbitragem, comentários ao texto complete da Lei 9.307, de 23 de setembro de 1996 com as alterações da Lei 13.129, de 26 de maio de 2015. Belo Horizonte: Francisco Maia \& Associados, 2015.

MANGE, Flavia Foz et al. $\mathbf{2}^{\mathbf{a}}$ Fase da Pesquisa Arbitragem e o Poder Judiciário: Relatório do tema: Homologação de Sentença Arbitral Estrangeira. s/d. Disponível em: < http://cbar.org.br/site/pesquisa-cbar-fgv-2007 >. Acesso em: 10 abr. 2016.

REZEK, José Francisco. Direito Internacional Público - curso elementar. 14a ed. São Paulo: Saraiva, 2013.

STJ, Notícias: Albert van den Berg: tribunais brasileiros precisam conhecer melhor a convenção de Nova Iorque. Disponível em: http://notadez.jusbrasil.com.br/noticias/100224404/stj-van-den-berg-tribunais-brasileiros-precisamconhecer-melhor-a-convencao-de-nova-iorque. 2013. Acesso em 9.abril.2016.

VAN DEN BERG, Albert Jan. The New York Convention and its Application by Brazilian Courts, in Revista de Arbitragem e Mediação, São Paulo: RT, nº 36, jan.-mar./2013, p. 15 e seguintes. 
VARELLA, Marcelo. Direito Internacional Público. 4a ed. São Paulo: Saraiva, 2012.

\section{Apêndice I - Pesquisa Jurisprudencial}

\begin{tabular}{|c|c|c|c|c|c|c|c|}
\hline Trib & $\begin{array}{c}\text { SEC } \\
\mathbf{N}^{\mathbf{0}}\end{array}$ & Rqte & Rqdo & Resultado & Data & Lei 9.307/96 & $\begin{array}{c}\text { Convenção } \\
\text { de Nova } \\
\text { Iorque }\end{array}$ \\
\hline$S T J$ & 856 & $L^{\prime}$ Aiglon $S / A$ & $\begin{array}{l}\text { Têxtil União } \\
\text { S/A }\end{array}$ & Homologada & $18 / 05 / 2005$ & $\begin{array}{l}\text { Art. 37(II) e } \\
38(I V) e(V)\end{array}$ & Art. II(2) \\
\hline STJ & 802 & $\begin{array}{l}\text { Thales } \\
\text { Geosolution }\end{array}$ & $\begin{array}{l}\text { Fonseca } \\
\text { Alemida }\end{array}$ & Homologada & $17 / 08 / 2005$ & & \\
\hline STJ & 887 & $\begin{array}{l}\text { Bouvery } \\
\text { International }\end{array}$ & $\begin{array}{l}\text { Irmãos } \\
\text { Pereira }\end{array}$ & Homologada & 06/03/2006 & $\begin{array}{l}\text { Art. } 35 \text { e } \\
38 \text { (III) }\end{array}$ & \\
\hline STJ & 967 & Plexus Cotton & $\begin{array}{l}\text { Santana } \\
\text { Têxtil S/A }\end{array}$ & $\begin{array}{l}\text { Não } \\
\text { Homologada }\end{array}$ & $3 / 15 / 2006$ & $\begin{array}{l}\text { Art. 37, } 38 \text { e } \\
\text { 39(II) }\end{array}$ & $\begin{array}{l}\text { Nos } \\
\text { Embargos } \\
\text { de } \\
\text { Declaração } \\
\text { Art. II } \\
\end{array}$ \\
\hline STJ & 874 & $\begin{array}{l}\text { Union } \\
\text { Europeénne de } \\
\text { Gymnastique }\end{array}$ & $\begin{array}{l}\text { Multipole } \\
\text { Distribuidora } \\
\text { de Filmes }\end{array}$ & Homologada & $19 / 04 / 2006$ & Art. 38 e 39 & \\
\hline STJ & 894 & $\begin{array}{l}\text { LITSA Líneas } \\
\text { de } \\
\text { Transmissión } \\
\text { del Litoral }\end{array}$ & $\begin{array}{l}\text { SV } \\
\text { Engenharia } \\
\text { S/A e Inepar }\end{array}$ & Homologada & $19 / 04 / 2006$ & $\begin{array}{l}\text { Art. } 31,38 \text { e } \\
39\end{array}$ & \\
\hline STJ & 866 & $\begin{array}{l}\text { Oleaginosa } \\
\text { Moreno }\end{array}$ & $\begin{array}{l}\text { Moinho } \\
\text { Paulista }\end{array}$ & $\begin{array}{l}\text { Não } \\
\text { Homologada }\end{array}$ & $17 / 05 / 2006$ & $\begin{array}{l}\text { Art. 37, 38(I) } \\
\text { e (II) e 39(II) }\end{array}$ & $\begin{array}{l}\text { Nos } \\
\text { Embargos } \\
\text { de } \\
\text { Declaração. } \\
\text { Art. II(2) } \\
\end{array}$ \\
\hline STJ & 760 & $\begin{array}{l}\text { Tremond } \\
\text { Alloys and } \\
\text { Metals }\end{array}$ & Metaltubos & Homologada & $19 / 06 / 2006$ & Art. $35-39$ & \\
\hline STJ & 968 & $\begin{array}{l}\text { Gottwald Port } \\
\text { Technology }\end{array}$ & Rodrimar S/A & $\begin{array}{l}\text { Extinta sem } \\
\text { julgamento } \\
\text { do mérito } \\
\end{array}$ & $30 / 06 / 2006$ & Art. 39 & \\
\hline STJ & 833 & $\begin{array}{l}\text { Subway } \\
\text { Partners C V }\end{array}$ & $\begin{array}{l}\text { HTTP High } \\
\text { Technology } \\
\text { Foods }\end{array}$ & $\begin{array}{l}\text { Não } \\
\text { Homologada }\end{array}$ & $16 / 08 / 2006$ & $\begin{array}{l}\text { Art. } 31,37(\text { II) } \\
\text { e } 39\end{array}$ & \\
\hline STJ & 507 & $\begin{array}{l}\text { Grain } \\
\text { Partners SPA }\end{array}$ & $\begin{array}{l}\text { Cooperativa } \\
\text { dos } \\
\text { Produtores e } \\
\text { Trabalhador } \\
\text { es de Sorriso } \\
\end{array}$ & Homologada & $18 / 10 / 2006$ & Art. 38 e 39 & $\begin{array}{l}\text { Nos } \\
\text { Embargos } \\
\text { de } \\
\text { Declaração }\end{array}$ \\
\hline
\end{tabular}




\begin{tabular}{|c|c|c|c|c|c|c|c|}
\hline Trib & $\begin{array}{c}\text { SEC } \\
\mathbf{N}^{\mathbf{o}}\end{array}$ & Rqte & Rqdo & Resultado & Data & Lei 9.307/96 & $\begin{array}{c}\text { Convenção } \\
\text { de Nova } \\
\text { Iorque }\end{array}$ \\
\hline STJ & 611 & $\begin{array}{l}\text { First Brands } \\
\text { do Brasil } \\
\text { LTDA e outro }\end{array}$ & $\begin{array}{l}\text { STP - } \\
\text { Petroplus } \\
\text { Produtos } \\
\text { automotivos }\end{array}$ & Homologada & $23 / 11 / 2006$ & Art. 37 e 38 & $\begin{array}{l}\text { Nos } \\
\text { Embargos } \\
\text { de } \\
\text { Declaração }\end{array}$ \\
\hline STJ & 349 & $\begin{array}{l}\text { Mitsubishi } \\
\text { Electric } \\
\text { Corporation }\end{array}$ & $\begin{array}{l}\text { Evadin } \\
\text { Indústrias } \\
\text { Amazônia }\end{array}$ & Homologada & $21 / 03 / 2007$ & Art. 38 e 39 & \\
\hline STJ & 839 & $\begin{array}{l}\text { Bouvery } \\
\text { International }\end{array}$ & $\begin{array}{l}\text { Valex } \\
\text { Exportadora } \\
\text { de Café }\end{array}$ & Homologada & $16 / 05 / 2007$ & Art. 38 & \\
\hline STJ & 1.210 & $\begin{array}{l}\text { International } \\
\text { Cotton } \\
\text { Trading }\end{array}$ & $\begin{array}{l}\text { Odil Pereira } \\
\text { Campos Filho }\end{array}$ & Homologada & $20 / 06 / 2007$ & $\begin{array}{l}\text { Art. } 37 \text { e } 38 \text { e } \\
39 \text { (II) }\end{array}$ & \\
\hline STJ & 918 & $\begin{array}{l}\text { Guidosimplex } \\
\text { Drive Ltda. }\end{array}$ & $\begin{array}{l}\text { Cavenaghi, } \\
\text { Cavenaghi e } \\
\text { Companhia }\end{array}$ & Homologada & 08/13/2007 & Art. 38 e 39 & \\
\hline STJ & 831 & $\begin{array}{l}\text { Spie } \\
\text { Enertrans }\end{array}$ & Inepar S/A & Homologada & 03/10/2007 & Art. 31-35 & Art. IV e V \\
\hline STJ & 1.305 & Nahuelsat S/A & Embratel & Homologada & $17 / 12 / 2007$ & & \\
\hline STJ & 1.302 & $\begin{array}{l}\text { Samsung } \\
\text { Amazonia }\end{array}$ & Gonçalves & Homologada & $18 / 06 / 2008$ & Art. 37 e 38 & \\
\hline STJ & 966 & $\begin{array}{l}\text { Econ } \\
\text { Agroindustrial }\end{array}$ & $\begin{array}{l}\text { Compania } \\
\text { Têxtil Pé da } \\
\text { Serra }\end{array}$ & $\begin{array}{l}\text { Extintas sem } \\
\text { julgamento } \\
\text { do mérito }\end{array}$ & $04 / 12 / 2008$ & & \\
\hline STJ & 978 & Indutech SPA & Algocentro & $\begin{array}{l}\text { Não } \\
\text { Homologada }\end{array}$ & $17 / 12 / 2008$ & & $\begin{array}{l}\text { Em } \\
\text { transcrição } \\
\text { de } \\
\text { jurisprudênc } \\
\text { ia Art. II(2) }\end{array}$ \\
\hline STJ & 3.661 & Plexus Cotton & Ari Giongo & Homologada & $28 / 05 / 2009$ & $\begin{array}{l}\text { Arts. } 34, \\
38(\text { III) e } 39\end{array}$ & \\
\hline STJ & 3.660 & Devcot S/A & Ari Giongo & Homologada & 28.05.2009 & $\begin{array}{l}\text { Art. } 34,38 \text { e } \\
39\end{array}$ & $\begin{array}{l}\text { Em } \\
\text { transcrição } \\
\text { de doutrina } \\
\text { Art. } \\
\text { V(1)"b" }\end{array}$ \\
\hline STJ & 3.035 & $\begin{array}{l}\text { Atec } \\
\text { Mannnesman }\end{array}$ & Rodrimar S/A & Homologada & 19.12.2009 & Art. 38 e 39 & \\
\hline STJ & 4.415 & $\begin{array}{l}\text { Jess Smith \& } \\
\text { Sons Cotton L }\end{array}$ & $\begin{array}{l}\text { Orlando } \\
\text { Polato }\end{array}$ & Homologada & 29.06 .2010 & Art. 38 & \\
\hline STJ & 4.980 & Paramount & $\begin{array}{l}\text { Lacoste do } \\
\text { Brasil }\end{array}$ & Homologada & 03.06 .2011 & Art. 38 e 39 & \\
\hline STJ & 4.439 & $\begin{array}{l}\text { Western Bulk } \\
\text { Carriers }\end{array}$ & A.P. Oxidos & Homologada & 24.11 .2011 & Art. $34-40$ & \\
\hline STJ & 6.365 & $\begin{array}{l}\text { Mandate } \\
\text { Holding }\end{array}$ & $\begin{array}{l}\text { Consórcio } \\
\text { Europa }\end{array}$ & Homologada & 06.02 .2012 & $\begin{array}{l}\text { Art. } 31,34 \text { e } \\
38 \text { e } 39\end{array}$ & \\
\hline
\end{tabular}




\begin{tabular}{|c|c|c|c|c|c|c|c|}
\hline Trib & $\begin{array}{c}\text { SEC } \\
\mathbf{N}^{0}\end{array}$ & Rqte & Rqdo & Resultado & Data & Lei 9.307/96 & $\begin{array}{c}\text { Convenção } \\
\text { de Nova } \\
\text { Iorque }\end{array}$ \\
\hline STJ & 1 & Kia Mortors & $\begin{array}{l}\text { Washinton } \\
\text { Armenio } \\
\text { Lopes }\end{array}$ & $\begin{array}{l}\text { Homologada } \\
\text { parcialmente }\end{array}$ & 01.03 .2012 & $\begin{array}{l}\text { Art. } 38(\text { IV) e } \\
\text { (V) e } 39(\text { II) }\end{array}$ & \\
\hline STJ & 885 & $\begin{array}{l}\text { Kanematsu } \\
\text { USA Inc. }\end{array}$ & $\begin{array}{l}\text { ATS } \\
\text { Advanced } \\
\text { Telecommuni } \\
\text { cations. }\end{array}$ & & 18.04 .2012 & Art. 37(II) & \\
\hline STJ & 3.709 & $\begin{array}{l}\text { Comverse } \\
\text { Inc. }\end{array}$ & $\begin{array}{l}\text { American } \\
\text { Telecomuuni } \\
\text { cations }\end{array}$ & Homologada & 14.07.2012 & $\begin{array}{l}\text { Lei 9.307/96, } \\
38(\text { II) e } 39\end{array}$ & Art. V(1)a \\
\hline STJ & 6.335 & $\begin{array}{l}\text { YPFB } \\
\text { Andinga S/A }\end{array}$ & $\begin{array}{l}\text { UNIVEN } \\
\text { Petroquímica. }\end{array}$ & Homologada & 15.08 .2012 & $\begin{array}{l}\text { Art. } 34 \text { e } 35 \\
\text { Art } 38 \text { e } 39\end{array}$ & \\
\hline STJ & 6.760 & $\begin{array}{l}\text { Queensland } \\
\text { Cotton }\end{array}$ & $\begin{array}{l}\text { Espólio de } \\
\text { Pedro Ivo } \\
\text { Freitas }\end{array}$ & Homologada & 25.04 .2013 & Art. 31 e 39 & \\
\hline STJ & 4.213 & $\begin{array}{l}\text { Jess Smith \& } \\
\text { Sons Cotton }\end{array}$ & $\begin{array}{l}\text { Espólio de } \\
\text { Pedro Ivo } \\
\text { Freitas }\end{array}$ & Homologada & 19.06 .2013 & Art. 38 e 39 & \\
\hline STJ & 5.828 & $\begin{array}{l}\text { Emanuele } \\
\text { Marchetti }\end{array}$ & $\begin{array}{l}\text { Marcos dos } \\
\text { Santos } \\
\text { Assunção }\end{array}$ & Homologada & 19.06 .2013 & Art. 38(II) & \\
\hline STJ & 6.753 & $\begin{array}{l}\text { Queensland } \\
\text { Cotton }\end{array}$ & $\begin{array}{l}\text { Ferticitrus } \\
\text { Agropastoril } \\
\text { Jotabasso }\end{array}$ & Homologada & 07.08 .2013 & Art. 38(II) & \\
\hline STJ & 4.024 & Keytrade AG & $\begin{array}{l}\text { Ferticitrus } \\
\text { Indústria e } \\
\text { Comércio de } \\
\text { Fertilizantes }\end{array}$ & Homologada & 07.08 .2013 & Art. 38 e 39 & \\
\hline STJ & 6.761 & $\begin{array}{l}\text { Olam } \\
\text { Intenational }\end{array}$ & $\begin{array}{l}\text { Sedeni Lucas } \\
\text { Lock }\end{array}$ & Homologada & 02.10 .2013 & Art. 38 e 39 & \\
\hline STJ & 3.891 & $\begin{array}{l}\text { Weil Brothers } \\
\text { Cotton Inc. }\end{array}$ & $\begin{array}{l}\text { Clóvis } \\
\text { Augustin }\end{array}$ & Homologada & 02.10 .2013 & Art. 38(II) & \\
\hline STJ & 4.516 & $\begin{array}{l}\text { Allstate } \\
\text { Insurance } \\
\text { Company }\end{array}$ & $\begin{array}{l}\text { Bradesco } \\
\text { Seguros S/A }\end{array}$ & Homologada & 16.10 .2013 & $\mathrm{n} / \mathrm{a}$ & \\
\hline STJ & 8.847 & $\begin{array}{l}\text { Paladin PM } \\
\text { Holmes Brazil }\end{array}$ & $\begin{array}{l}\text { Molnar } \\
\text { Construtora }\end{array}$ & Homologada & 20.11.2013 & Art. 39 & $\begin{array}{l}\text { Referência } \\
\text { no relatório }\end{array}$ \\
\hline STJ & 2.410 & $\begin{array}{l}\text { Construccione } \\
\text { s y Auxiliar de } \\
\text { Ferrocarrile }\end{array}$ & $\begin{array}{l}\text { Supervia } \\
\text { Concessionári } \\
\text { a de } \\
\text { Transportes }\end{array}$ & $\begin{array}{l}\text { Homologaçã } \\
\text { o Parcial }\end{array}$ & 18.12.2013 & Art. 39 & \\
\hline STJ & 9.714 & $\begin{array}{l}\text { Tristão } \\
\text { Trading }\end{array}$ & $\begin{array}{l}\text { Naumann } \\
\text { Geep }\end{array}$ & Homologada & 27.05 .2014 & Art. 38 e 39 & \\
\hline STJ & 9.502 & $\begin{array}{l}\text { Russakaya } \\
\text { Kozha }\end{array}$ & Courama & Homologada & 01.07 .2014 & $\begin{array}{l}\text { Art. } 38(\mathrm{III}) \mathrm{e} \\
39\end{array}$ & \\
\hline STJ & 9.880 & $\begin{array}{l}\text { Cimc Raffles } \\
\text { Offshore }\end{array}$ & $\begin{array}{l}\text { Schahim } \\
\text { Holdiong S/A } \\
\text { e outros }\end{array}$ & Homologada & 05.08 .2014 & $\begin{array}{l}\text { Art. } 37,38 \text { e } \\
39\end{array}$ & \\
\hline
\end{tabular}




\begin{tabular}{|c|c|c|c|c|c|c|c|}
\hline Trib & $\begin{array}{c}\text { SEC } \\
\mathbf{N}^{\mathbf{o}}\end{array}$ & Rqte & Rqdo & Resultado & Data & Lei $9.307 / 96$ & $\begin{array}{c}\text { Convenção } \\
\text { de Nova } \\
\text { Iorque }\end{array}$ \\
\hline STJ & 5.692 & $\begin{array}{l}\text { Newedge USA } \\
\text { LLC }\end{array}$ & $\begin{array}{l}\text { Manoel } \\
\text { Fernando } \\
\text { Garcia } \\
\end{array}$ & Homologada & 20.08 .2014 & Art. 38 e 39 & \\
\hline STJ & 10.658 & $\begin{array}{l}\text { Helsingborgs } \\
\text { IF }\end{array}$ & $\begin{array}{l}\text { Otto Cracco } \\
\text { \& Behling } \\
\text { Ltda. EPP }\end{array}$ & Homologada & 01.10 .2014 & $\begin{array}{l}\text { Art. } 37,38 \mathrm{e} \\
39\end{array}$ & \\
\hline STJ & 10.643 & $\begin{array}{l}\text { Casio } \\
\text { Computer Co. }\end{array}$ & $\begin{array}{l}\text { Eletronicos } \\
\text { Princi }\end{array}$ & Homologada & 19.11 .2014 & $\begin{array}{l}\text { Arts. } 37,38 \mathrm{e} \\
39\end{array}$ & \\
\hline STJ & 3.892 & $\begin{array}{l}\text { Jess Smith \& } \\
\text { Sons Cotton }\end{array}$ & $\begin{array}{l}\text { Agropecuária } \\
\text { Basso Ltda. }\end{array}$ & Homologada & 19.11 .2014 & Arts. 34-40 & \\
\hline STJ & 11.529 & $\begin{array}{l}\text { Al Gharafa } \\
\text { Sports Club }\end{array}$ & $\begin{array}{l}\text { Clemenson } \\
\text { de Araujo } \\
\text { Soares }\end{array}$ & Homologada & 17.12 .2014 & Arts. 34 e 39 & \\
\hline STJ & 10.702 & $\begin{array}{l}\text { Asia Steel and } \\
\text { Metals }\end{array}$ & $\begin{array}{l}\text { Mineração } \\
\text { Vila Nova }\end{array}$ & Homologada & 04.03 .2015 & Art. 37 & \\
\hline STJ & 8.242 & $\begin{array}{l}\text { Huawei do } \\
\text { Brasil }\end{array}$ & $\begin{array}{l}\text { Zune } \\
\text { Consultoria }\end{array}$ & Homologada & 04.03 .2015 & Art. 38 e 39 & \\
\hline STJ & 5782 & $\begin{array}{l}\text { EDF } \\
\text { International }\end{array}$ & $\begin{array}{l}\text { Endessa } \\
\text { Latinoaméri } \\
\text { ca }\end{array}$ & $\begin{array}{l}\text { Não } \\
\text { homologada }\end{array}$ & 02.12.2015 & Art. 38(VI) & $\begin{array}{l}\text { Art. V(1) } \\
\text { "e" }\end{array}$ \\
\hline STJ & 11.593 & $\begin{array}{l}\text { Biglift } \\
\text { Shipping Bv }\end{array}$ & $\begin{array}{l}\text { Transdata } \\
\text { Transportes }\end{array}$ & & 18.12 .2015 & Art. $4, \S 1^{\circ} \mathrm{da}$ & \\
\hline STJ & 12.236 & $\begin{array}{l}\text { Thyssenkrupp } \\
\text { Steel Europe }\end{array}$ & $\mathrm{CSN}$ & $\begin{array}{l}\text { Não } \\
\text { Homologada }\end{array}$ & 18.12 .2015 & $\begin{array}{l}\text { Art. } 37,38 \text { e } \\
39\end{array}$ & \\
\hline STJ & 11.969 & C M G C K & $\begin{array}{l}\text { M S/A e T I } \\
\text { S/A }\end{array}$ & Homologada & 02.02 .2016 & $\begin{array}{l}\text { Arts. } 24-40 \\
\text { Art. } 34\end{array}$ & \\
\hline
\end{tabular}

